\title{
Analisis Keranjang Belanja Pada Transaksi Penjualan Menggunakan Algoritma Apriori
}

\author{
Retno Sari $^{1}{ }^{*}$, Ratih Yulia Hayuningtyas ${ }^{2}$ \\ ${ }^{1}$ Teknik Informatika, Sekolah Tinggi Manajemen Informatika dan Komputer Nusa Mandiri \\ Indonesia \\ ${ }^{2}$ Teknik Informatika, Sekolah Tinggi Manajemen Informatika dan Komputer Nusa Mandiri \\ Indonesia \\ *Corresponding Author.E-mail:retno.rnr@nusamandiri.ac.id,ratih.ryl@nusamandiri.ac.id
}

\begin{abstract}
Abstrak
Data pada transaksi penjualan dapat diolah menjadi informasi yang dapat dimanfaatkan untuk mengetahui perilaku konsumen. Informasi ini dapat dimanfaatkan pelaku usaha untuk memudahkan dalam proses stok barang, analisis, retensi pelanggan dan deteksi penipuan. Tujuan dari penelitian ini yaitu untuk mengetahui perilaku pembeli pada keranjang belanja untuk mengetahui menu makanan pada restoran yang diminati. Analisis keranjang belanja ini dilakukan dengan mengimplementasikan algoritma apriori untuk mengetahui aturan asosiasi pada setiap itemset, pada penelitian ini dilakukan dengan melakukan aturan kombinasi 3 itemset. Pada penelitian ini ditentukan untuk nilai support minimumnya sebesar $20 \%$ dan nilai minimum confidencenya sebesar 50\%. Didapati bahwa konsumen sering membeli gurame bakar, kangkung, karedok, tahu goreng (isi 5pcs), tahu ondel (isi 5pcs), toge cah bawang putih.
\end{abstract}

\begin{abstract}
Data on sales transactions can be processed into information that can be used to determine consumer behavior. This information can be used by business actors to facilitate the process of stocking goods, analysis, customer retention and fraud detection. The purpose of this study is to determine the behavior of buyers in the shopping cart to find out the food menu at the restaurant of interest. This shopping cart analysis is carried out by implementing the a priori algorithm to find out the association rules for each itemset, in this study it was carried out by implementing a combination of 3 itemset rules. In this study, the minimum support value is $20 \%$ and the minimum confidence value is 50\%. It was found that consumers often buy grilled carp, kale, karedok, fried tofu (contains 5pcs), ondel tofu (contains 5pcs), garlic chopped bean sprouts.
\end{abstract}

Keywords: Algorima Apriori; Keranjang Belanja; Transaksi Penjualan

\section{Introduction}

Data mining merupakan proses menemukan sesuatu yang berharga dari banyak data. Data mining saat ini menjadi perhatian dikarenakan dengan data yang dimiliki dalam jumlah yang besar dapat diubah menjadi informasi dan pengetahuan yang dapat digunakan untuk melakukan 
analisis, deteksi penipuan, retensi pelanggan hingga control produksi dan sains (Han \& Kamber, 2006).

Transaksi perdagangan yang banyak dapat dijadikan informasi yang bermanfaat setelah diolah datanya (Rodiyansyah, 2015). Penerapan algoritma apriori pada $e$ commerce dapat menganalisis perilaku pembeli sehingga memudahkan dalam proses stok barang (Aditya, Marisa, \& Purnomo, 2016). Algoritma apriori digunakan untuk menganalisa barang yang diminati pembeli untuk melakukan stok barang (Tampubolon, Saragih, \& Reza, 2013).

Analisis asosiasi merupakan salah satu cara untuk mengetahui relasi antara kombinasi item, relasi ini digambarkan dalam bentuk aturan asosiasi (Gama, Putra, \& Bayupati, 2016).

Telah dilakukan penelitian sebelumnya dengan judul implementasi algoritma apriori untuk mencari assiasi barang yang dijual di e-commerce OrderMas, pada penelitian ini dilakukan uji analisis dengan mengatur 2 atau 3 itemset barang yang sering dibeli oleh konsumen secara bersamaan dan didapatkan bahwa konsumen sering membeli pink fairy cake, doormat new englang dan doormat fairy cake. Dengan aturan asosiasi untuk A2=>A9 di dapati nilai confidence $100 \%$, untuk aturan asosiasi $\mathrm{A} 7=>\mathrm{A} 9$ didapati nilai confidence 83\% (Sholik \& Salam, 2018).

Penelitian yang telah dilakukan sebelumnya dengan judul implementasi algoritma apriori dalam menentukan program studi yang diambil mahasiswa, pada penelitian ini mengkombinasikan hingga 4 itemset, pada penelitian ini di dapatkan nilai strong confidence paling tinggi 75\% (Fajri, 2016).

Penelitian yang telah dilakukan sebelumnya dengan judul penerapan data mining penjualan sepatu menggunakan metode algoritma apriori, dilakukan kombinasi sampai dengan 3 item dengan minimal support $30 \%$ dan minimal confidence $60 \%$, pada penelitian ini diketahui jenis sepatu yang paling banyak diminati konsumen yaitu Nike, Adidas, New Balance, Geox dan Palladium (Sikumbang, 2018).

Tujuan dari penelitian ini yaitu ingin mengetahui perilaku pembeli untuk analisis keranjang belanja pada transaksi penjualan untuk mengetahui makanan apa yang diminati.

\section{Materials and Methods}

Berikut tahapan pada penelitian ini:

a. Pengumpulan Data 
Pada penelitian ini penulis melakukan pengumpulan data transaksi penjualan makanan.

b. Pembersihan Data

Pada tahap ini, penulis melakukan pembersihan data dengan menghilangkan data transaksi yang sama.

c. Metode yang digunakan

Metode yang digunakan yaitu algoritma apriori, untuk mengetahui aturan asosiasi pada transaksi penjualan.

Algoritma apriori merupakan teknik data mining untuk mengetahui ketentuan asosiasi antara kombinasi item (Rodiyansyah, 2015).

Pada algoritma ini memiliki dua tolak ukur, yaitu support dan confidence. Support (nilai penunjang) yang merupakan persentase kombinasi item, confidence (nilai kepastian) yaitu hubungan antar item pada relasi asosiasi(Valerian \& Hakim, 2018).

Persamaan untuk menghitung nilai support 1 item set (Silvia \& Sundari, 2020):

Support $(A)=\frac{\sum \text { transaksi mengadung A } \times 100 \%}{\sum \text { transaksi }}$

Persamaan untuk menghitung nilai support 2 item set:

Support $(A, B)=\frac{\sum \text { transaksi mengadung A dan B x 100\% }}{\sum \text { transaksi }}$

Persamaan untuk menghitung nilai support 3 item set :

Support $(A, B, C)=\frac{\sum \text { transaksi mengadung A, B dan C x 100\% }}{\sum \text { transaks }}$
Persamaan untuk mendapatkan nilai confidence dari aturan $\mathrm{A} \rightarrow \mathrm{B}$ yaitu:

Confidence $=\frac{\sum \text { transaksi mengadung A dan B x 100\% }}{\sum \text { transaksi mengandung A }}$

\section{Results and Discussion}

Dataset diambil dari transaksi penjualan makanan.

Tabel 1 Data Makanan

\begin{tabular}{cl}
\hline ID Makanan & \multicolumn{1}{c}{ Nama Makanan } \\
\hline A1 & Cumi Goreng - M \\
A2 & Gurame Bakar \\
A3 & Gurame Goreng Kering \\
A4 & Kangkung \\
A5 & Karedok \\
A6 & Mie Goreng Ayam \\
& Mix Seafood Singapore Chili Sauce \\
A7 & (Spicy) \\
A8 & Sambal Mangga \\
A9 & Sambal Terasi \\
A10 & Tahu Goreng (isi 5 pcs) \\
A11 & Tahu Ondel (isi 5 pcs) \\
A12 & Toge Cah Bawang Putih \\
\hline
\end{tabular}

Tabel 2 Data Transaksi

\begin{tabular}{cl}
\hline ID Transaksi & \multicolumn{1}{c}{ Yang dibeli } \\
\hline$\# 1006$ & A12,A4,A8 \\
$\# 1007$ & A1 \\
$\# 1008$ & A10,A12,A5,A6 \\
$\# 1012$ & A1,A11,A12,A3,A4,A8 \\
$\# 1014$ & A1,A11,A2,A4 \\
$\# 1015$ & A1,A9 \\
$\# 1016$ & A2,A5 \\
$\# 1019$ & A10,A2,A3,A5,A9 \\
$\# 1020$ & A1,A7 \\
$\# 1021$ & A2 \\
\hline
\end{tabular}

Data transaksi dijabarkan dalam bentuk tabular seperti tabel dibawah ini:

Tabel 3 Bentuk Tabular transaksi

\begin{tabular}{lrrrrrrrrrrrr}
\hline ID & A1 & A2 & A3 & A4 & A5 & A6 & A7 & A8 & A9 & A10 & A11 & A12 \\
\hline$\# 1006$ & 0 & 0 & 0 & 1 & 0 & 0 & 0 & 1 & 0 & 0 & 0 & 1 \\
$\# 1007$ & 1 & 0 & 0 & 0 & 0 & 0 & 0 & 0 & 0 & 0 & 0 & 0 \\
\hline
\end{tabular}




\begin{tabular}{|c|c|c|c|c|c|c|c|c|c|}
\hline$\# 1008$ & 0 & 0 & 0 & 0 & 1 & 1 & 0 & 0 & 0 \\
\hline$\# 1012$ & 1 & 0 & 1 & 1 & 0 & 0 & 0 & 1 & 0 \\
\hline$\# 1014$ & 1 & 1 & 0 & 1 & 0 & 0 & 0 & 0 & 0 \\
\hline \#1015 & 1 & 0 & 0 & 0 & 0 & 0 & 0 & 0 & 1 \\
\hline \#1016 & 0 & 1 & 0 & 0 & 1 & 0 & 0 & 0 & 0 \\
\hline$\# 1019$ & 0 & 1 & 1 & 0 & 1 & 0 & 0 & 0 & 1 \\
\hline$\# 1020$ & 1 & 0 & 0 & 0 & 0 & 0 & 1 & 0 & 0 \\
\hline$\# 1021$ & 0 & 1 & 0 & 0 & 0 & 0 & 0 & 0 & 0 \\
\hline \multicolumn{10}{|c|}{$\begin{array}{l}\text { Pada tabel bentuk tabular transaksi } \\
\text { an jumlah minimum support } 20 \%\end{array}$} \\
\hline \multicolumn{10}{|c|}{ Tabel 4 Nilai Support dari setiap makanan } \\
\hline \multicolumn{3}{|c|}{ ID Makanan } & \multicolumn{5}{|c|}{ Proses Support } & \multicolumn{2}{|c|}{ support } \\
\hline \multicolumn{3}{|c|}{ A1 } & \multicolumn{4}{|c|}{$(5 / 10) \times 100$} & & \multicolumn{2}{|c|}{$50 \%$} \\
\hline \multicolumn{3}{|c|}{$\mathrm{A} 2$} & \multicolumn{4}{|c|}{$(4 / 10) \times 100$} & & \multicolumn{2}{|c|}{$40 \%$} \\
\hline \multicolumn{3}{|c|}{ A3 } & \multicolumn{4}{|c|}{$(2 / 10) \times 100$} & & \multicolumn{2}{|c|}{$20 \%$} \\
\hline \multicolumn{3}{|c|}{ A4 } & \multicolumn{4}{|c|}{$(3 / 10) \times 100$} & & \multicolumn{2}{|c|}{$30 \%$} \\
\hline \multicolumn{3}{|c|}{ A5 } & \multicolumn{4}{|c|}{$(3 / 10) \times 100$} & & \multicolumn{2}{|c|}{$30 \%$} \\
\hline \multicolumn{3}{|c|}{ A6 } & \multicolumn{4}{|c|}{$(1 / 10) \times 100$} & & \multicolumn{2}{|c|}{$10 \%$} \\
\hline \multicolumn{3}{|c|}{ A7 } & \multicolumn{4}{|c|}{$(1 / 10) \times 100$} & & \multicolumn{2}{|c|}{$10 \%$} \\
\hline \multicolumn{3}{|c|}{ A8 } & \multicolumn{4}{|c|}{$(2 / 10) \times 100$} & & \multicolumn{2}{|c|}{$20 \%$} \\
\hline \multicolumn{3}{|c|}{ A9 } & \multicolumn{4}{|c|}{$(2 / 10) \times 100$} & & \multicolumn{2}{|c|}{$20 \%$} \\
\hline \multicolumn{3}{|c|}{ A10 } & & $2 / 1$ & $x 100$ & & & & $\%$ \\
\hline & A1 & & & $2 / 1$ & $x 100$ & & & & $\%$ \\
\hline & A12 & & & $3 / 1$ & $\times 100$ & & & & $\%$ \\
\hline
\end{tabular}

Dari tabel diatas terdapat kode barang yang memenuhi minimum support $20 \%$, yaitu $\mathrm{A} 1$, A2, A3, A4, A5, A8, A9, A10, A11 dan A12.

Kombinasi 2 itemset dengan memasangkan satu item dengan item lainnya.

Tabel 5 Kombinasi 2 itemset

\begin{tabular}{lrlr}
\hline Kode Barang & Jumlah & Proses Support & \multicolumn{1}{c}{ Support } \\
\hline A1-A2 & 1 & $1 / 10 \times 100$ & $10 \%$ \\
A1-A3 & 1 & $1 / 10 \times 100$ & $10 \%$ \\
A1-A4 & 2 & $2 / 10 \times 100$ & $20 \%$ \\
A1-A5 & 0 & $0 / 10 \times 100$ & $0 \%$ \\
A1-A6 & 0 & $0 / 10 \times 100$ & $0 \%$ \\
A1-A7 & 1 & $1 / 10 \times 100$ & $10 \%$ \\
A1-A8 & 1 & $1 / 10 \times 100$ & $10 \%$ \\
A1-A9 & 1 & $1 / 10 \times 100$ & $10 \%$ \\
A1-A10 & 0 & $0 / 10 \times 100$ & $0 \%$ \\
A1-A11 & 2 & $2 / 10 \times 100$ & $20 \%$ \\
A1-A12 & 1 & $1 / 10 \times 100$ & $10 \%$ \\
A2-A3 & 1 & $1 / 10 \times 100$ & $10 \%$ \\
A2-A4 & 1 & $1 / 10 \times 100$ & $10 \%$ \\
A2-A5 & 2 & $2 / 10 \times 100$ & $20 \%$ \\
\hline A2-A6 & 0 & $0 / 10 \times 100$ & $0 \%$
\end{tabular}

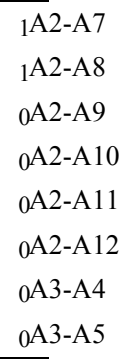


Kombinasi 2 itemset dengan minimum support $20 \%$ didapatkan frequent 2 itemset sebagai berikut :

$\mathrm{F} 2=[\mathrm{A} 1, \mathrm{~A} 4],[\mathrm{A} 1, \mathrm{~A} 11],[\mathrm{A} 2, \mathrm{~A} 5],[\mathrm{A} 4, \mathrm{~A} 11]$, [A4,A12], [A5,A10]

Kombinasi 3 itemset juga sama dengan memasangkan item satu dengan item lainnya sehingga membentuk 3 itemset.

Tabel 6 Kombinasi 3 itemset

\begin{tabular}{lclr}
\hline Kode & & Proses & \\
Barang & Jumlah & Support & Support \\
\hline A1-A2-A3 & 0 & $0 / 10 \times 100$ & $0 \%$ \\
A3-A4-A5 & 0 & $0 / 10 \times 100$ & $0 \%$ \\
A6-A7-A8 & 0 & $0 / 10 \times 100$ & $0 \%$ \\
A9-A10-A11 & 0 & $0 / 10 \times 100$ & $0 \%$ \\
A10-A11- & & & \\
A12 & 0 & $0 / 10 \times 100$ & $0 \%$ \\
\hline
\end{tabular}

Kombinasi 3 itemset tidak ada yang memenuhi minimum support $20 \%$.

Kombinasi 2 itemset yang memenuhi pembentukan asosiasi sebagai berikut:

Tabel 7 Asosiasi Kombinasi 2 Itemset

\begin{tabular}{llr}
\hline Kode & Proses & \\
Barang & Confidence & Confidence \\
\hline $\mathrm{A} 1 \rightarrow \mathrm{A} 4$ & $2 / 5 \times 100$ & $40 \%$ \\
$\mathrm{~A} 1 \rightarrow \mathrm{A} 11$ & $2 / 5 \times 100$ & $40 \%$ \\
$\mathrm{~A} 2 \rightarrow \mathrm{A} 5$ & $2 / 4 \times 100$ & $50 \%$ \\
$\mathrm{~A} 4 \rightarrow \mathrm{A} 11$ & $2 / 3 \times 100$ & $66,7 \%$ \\
$\mathrm{~A} 4 \rightarrow \mathrm{A} 12$ & $2 / 3 \times 100$ & $66,7 \%$ \\
$\mathrm{~A} 5 \rightarrow \mathrm{A} 10$ & $2 / 3 \times 100$ & $66,7 \%$ \\
\hline
\end{tabular}

Dari asosiasi kombinasi 2itemset diatas yang memenuhi minimum confidence $50 \%$ terdapat 4 aturan.

Tabel 8 Asosiasi Kombinasi 2 Itemset yang memenuhi minimum confidence

\begin{tabular}{llr}
\hline Kode & Proses & \\
Barang & Confidence & Confidence \\
\hline A2 $\rightarrow$ A5 & $2 / 4 \times 100$ & $50 \%$ \\
A4 $\rightarrow$ A11 & $2 / 3 \times 100$ & $66,7 \%$ \\
A4 $\rightarrow$ A12 & $2 / 3 \times 100$ & $66,7 \%$
\end{tabular}

$$
\mathrm{A} 5 \rightarrow \mathrm{A} 10 \quad 2 / 3 \times 100 \quad 66,7 \%
$$

Dari tabel diatas menunjukan nilai asosiasi, bahwa konsumen sering membeli gurame bakar, kangkung, karedok, tahu goreng (isi $5 \mathrm{pcs}$ ), tahu ondel (isi 5pcs), toge cah bawang putih.

\section{Conclusion}

Kesimpulan yang diambil dari penelitian analisis keranjang belanja pada transaksi penjualan, dengan nilai support minimum $20 \%$ dan nilai confidence minimum 50\% ditemukan aturan asosiasi $\mathrm{A} 2 \rightarrow \mathrm{A} 5$, $\mathrm{A} 4 \rightarrow \mathrm{A} 11, \mathrm{~A} 4 \rightarrow \mathrm{A} 12$ dan $\mathrm{A} 5 \rightarrow \mathrm{A} 10$. Nilai asosiasi tersebut menunjukkan bahwa konsumen sering membeli gurame bakar, kangkung, karedok, tahu goreng (isi 5pcs), tahu ondel (isi 5pcs), toge cah bawang putih.

\section{References}

Aditya, Marisa, F., \& Purnomo, D. (2016). Penerapan Algoritma Apriori Terhadap Data Penjualan di Toko Gudang BM. JOINTECS (Journal of Information Technology and Computer Science), 1(1), 1-5. https://doi.org/10.31328/jointecs.v1i1.4 08

Fajri, A. F. (2016). Implementasi Algoritma Apriori Dalam Menetukan Program Studi Yang Diambil Mahasiswa. Jurnal Iptek Terapan, 10(2), 81-85. https://doi.org/10.22216/jit.2016.v10i2. 402

Gama, A. W. O., Putra, I. K. G. D., \& Bayupati, I. P. A. (2016). Implementasi Algoritma Apriori Untuk Menemukan Frequent Itemset Dalam Keranjang Belanja. Majalah Ilmiah Teknologi 
Elektro, 15(2), 21-26. https://doi.org/10.24843/mite.1502.04

Han, J., \& Kamber, M. (2006). Data Mining: Concepts and Techniques (Second Edi). Elsevier.

Rodiyansyah, S. (2015). Algoritma Apriori untuk Analisis Keranjang Belanja pada Data Transaksi Penjualan. Infotech Journal, 1(2), 236599.

Sholik, M., \& Salam, A. (2018). Implementasi Algoritma Apriori untuk Mencari Asosiasi Barang yang Dijual di E-commerce OrderMas. Techno.COM, 17(2), 158-170.

Sikumbang, E. D. (2018). Penerapan Data Mining Penjualan Sepatu Menggunakan Metode Algoritma Apriori. Jurnal Teknik Komputer AMIK BSI (JTK), Vol 4,
No.(September), 1-4.

Silvia, L., \& Sundari, J. (2020). Penerapan Algoritma Apriori Untuk Menentukan Impor Barang Pada PT . Pada Mandiri Sakti. Processor, 15(1), 54-61.

Tampubolon, K., Saragih, H., \& Reza, B. (2013). Implementasi Data Mining Algoritma Apriori Pada Sistem Persediaan Alat-alat Kesehatan. Majalah Ilmiha Informasi Dan Teknologi Ilmihan (INTI), 1(1), 93106.

https://doi.org/10.1017/S0079497X000 14341

Valerian, A., \& Hakim, L. (2018). Implementasi Algoritma Apriori Untuk Prediksi Stok Peralatan Tulis Pada Toko XYZ. Jurnal Ilmiah Teknologi Informasi Terapan, V(1), 18-22. 